\title{
Sources of tobacco for youths in communities with strong enforcement of youth access laws
}

\author{
Joseph R DiFranza, Mardia Coleman
}

\begin{abstract}
Aim-To determine how youths obtain tobacco in communities with strong enforcement of tobacco sales laws. Setting-Ten communities in Massachusetts with merchant compliance rates at or above $90 \%$.

Methods-Paper surveys and focus group discussions with 68 adolescent smokers.

Results-Parents and friends are the primary sources of tobacco for new smokers. When stealing from parents can no longer satisfy the need for cigarettes, young adolescents ask strangers to buy them tobacco. For high school age smokers, teenage store clerks are a major source. Teenage clerks sell to other teenagers, steal tobacco, and help their friends steal from their employers. Friends who are 18 years of age or over are a second major source for older adolescents. Parents often purchase tobacco for older adolescents.

Conclusion-Recommended actions include raising the minimum age for the purchase of tobacco to 21 years, and prohibiting individuals less than 21 years of age from selling tobacco.

(Tobacco Control 2001;10:323-328)
\end{abstract}

Keywords: youth; youth access laws

Research has identified a variety of mechanisms by which youths obtain tobacco. ${ }^{1-12}$ Younger smokers tend to borrow cigarettes from their friends, while older adolescents are more likely to purchase directly from stores. ${ }^{48}$ Additional sources are relatives, shoplifting, vending machines, or third party purchases by strangers or older friends. ${ }^{13} 46810$

Interventions to prevent the sale of tobacco to minors have reduced youth tobacco use in some studies, ${ }^{13-16}$ but not all, ${ }^{6}{ }^{17}$ suggesting that access was not uniformly restricted in these studies. How do youths obtain tobacco in communities where tobacco sales laws are well enforced? If neighbourhood youths can purchase tobacco from the same retailers who refuse to sell to underage decoys, more effective approaches to halting illegal sales will be needed. On the other hand, if the impact of enforcement is blunted because youths switch to social sources of tobacco such as parents or older friends, efforts to reduce access must extend to these sources. This study enlisted focus groups to investigate the methods used to obtain tobacco by underage smokers living in communities with strong enforcement programmes.

\begin{abstract}
Methods
SETTING

Ten Massachusetts communities were identified as having achieved compliance rates of $90 \%$ or greater during enforcement inspections by local officials using underage decoys. The communities, all suburbs and small cities, had adopted many restrictions on self-service displays and vending machines. The sale of tobacco to anyone under 18 years of age was illegal, but the possession of tobacco was not.
\end{abstract}

\section{SUBJECTS}

The subjects were smokers, ages $12-19$ years, recruited by school personnel. One group was recruited from a population involved in a longitudinal study of tobacco use. ${ }^{18}$

\section{PROCEDURE}

The study was approved by the Committee for the Protection of Human Subjects in Research at the University of Massachusetts Medical School. Informed consent was obtained. A series of 10 focus groups were conducted with four to eight participants. Subjects were promised confidentiality and received lunch and a $\$ 25$ stipend for their participation. Before the discussion, subjects completed a questionnaire concerning their sources of tobacco. The authors moderated the sessions. Tape recordings were made and transcribed, but the identity of individual subjects could not be determined from the tapes. During the sessions, the authors took notes which were discussed after the subjects left. The discussion questions were adapted over time to explore emerging themes. Examples of starter questions include: "The health department in this community thinks it is just about impossible for kids under 18 to buy tobacco in this town. Are they right?"; "When the health department wants to see if a store will sell to kids, they hire a kid who has never smoked to try to buy cigarettes ... do you think you could do better at buying tobacco than these kids?"

DATA ANALYSIS

The notes and transcripts were reviewed for common themes. The surveys were analysed for frequency distributions. Student's $t$ test was used for the comparison of means. A probability value of $p<0.05$ was used as a test of significance.

\section{Results}

SURVEYS

Sixty eight subjects participated, and $68 \%$ were female. The mean age was 16 years. No other demographic information was collected. The mean age for the first puff on a cigarette was 
Table 1 Ranking of sources of tobacco according to whether youths had ever acquired tobacco from each source

\begin{tabular}{lc} 
Have you ever gotten cigarettes from any of these sources? ( $n=68)$ \\
\hline Friends & $99 \%$ \\
Gave someone over 18 money to buy them & $94 \%$ \\
Bought it from a store & $89 \%$ \\
Gave money to a stranger to buy for me & $72 \%$ \\
Relative other than parents or siblings & $69 \%$ \\
Gave someone under 18 money to buy them & $68 \%$ \\
Got it from brother or sister & $60 \%$ \\
Stole from parent & $59 \%$ \\
Bought it from a vending machine & $44 \%$ \\
Stole it from a store & $43 \%$ \\
My parent gave it to me & $42 \%$ \\
\hline
\end{tabular}

* Includes only youths under 18 years of age $(\mathrm{n}=55)$.

Table 2 Ranking of sources of tobacco according to how frequently youths reported obtaining tobacco from each source

How often have you gotten cigarettes from each of these sources?

How often
$(n=68)$

\begin{tabular}{|c|c|}
\hline Source & Meant \\
\hline Friends gave them & 2.5 \\
\hline Gave someone over 18 money to buy them for me & 2.2 \\
\hline Bought them in a store ${ }^{\star}$ & 2.1 \\
\hline Gave money to a stranger to buy them for me & 1.3 \\
\hline Gave money to someone under 18 to buy them for me & 1.2 \\
\hline Brother or sister gave them & 1.1 \\
\hline My parent gave them to $m e^{\star}$ & 1.1 \\
\hline Stole them from a parent or relative & 1.1 \\
\hline Other relative gave them & 1.0 \\
\hline Bought from a vending machine ${ }^{\star}$ & 0.7 \\
\hline Stole from a store & 0.5 \\
\hline
\end{tabular}

11.7 years $(n=66)$. Youths who had stolen tobacco from a parent reported a mean age for the first puff (11.3 years), one year earlier than youths who had never stolen tobacco from a parent $(12.3$ years, $n=66, p=0.05)$

All subjects had smoked cigarettes $-88 \%$ were daily smokers, $82 \%$ had smoked a cigar, and $29 \%$ had used smokeless tobacco. The subjects smoked a mean of 86 cigarettes per week with a range from $1-220$. Table 1 ranks sources of tobacco according to whether youths had ever acquired tobacco from each source. Table 2 ranks the same sources according to how frequently youths reported obtaining tobacco from each source. Of those subjects who had tried to purchase tobacco from a store $(\mathrm{n}=64), 81 \%$ had at some time lied about their age, and $24 \%$ had used a fake ID $(n=63)$. When asked on a four point scale how frequently they were turned down in their efforts to purchase tobacco, subjects under 18 years of age gave a mean score of 1.8 , with 1 indicating "hardly ever" and 2 indicating "sometimes" $(\mathrm{n}=51)$.

FOCUS GROUPS

Role of parents and family

Parents were overwhelmingly the primary source of tobacco for youths at the onset of smoking.

Moderator: "How important are your parents for getting tobacco when you were like in junior high? I'm assuming they didn't buy you cigarettes when you were in 7 th grade?"

Subject 1: "No."

Moderator: "But you took them from them? Was that a major source of your tobacco?"
Subject 1: "Yeah."

Subject 2: "Yup."

Subject 3: "In the beginning it was, yeah."

Subject 4: "I never did. My friends always used to have a pack."

Moderator: "Well, where did your friend get them?

Subject 4: "From his parents."

Half smoked cigarettes in the ashtrays of relatives were a common source. It appears that many youths become addicted with the cigarettes stolen from parents. As tolerance develops and their consumption increases, they need to develop additional sources.

"So, that's when we really got hooked and we started like going to stores and asking other people."

In later adolescence, adult family members play a large role in undermining access restrictions by buying cigarettes for their children and their friends. A parent who supplies their child with tobacco is supplying all of the child's friends as well.

Moderator: "Does your mother buy $100 \%$ of the tobacco for you?"

Subject: "Yes."

"My mother buys me cigarettes almost every other day."

"My parents won't buy for me, but they'll buy for her and all my other friends."

"My mother will buy them for my friends but not me."

It is commonplace for youths to forgo lunch and use lunch money supplied by parents to buy cigarettes.

\section{Shoulder tapping}

When cigarettes stolen from home are no longer sufficient to satisfy young smokers, but they are still too young to buy in stores, it is commonplace for them to loiter in front of stores asking strangers to buy for them. This is commonly viewed as an act of desperation.

"I hate that, when you ask someone to buy you cigarettes and people come up to you like, 'my grandfather died of that'. I hate that."

Some subjects indicated that finding a cooperative stranger was easy, while others found it quite difficult. Youths learned which types of people would be more likely to buy for them, described as smokers, young men, and shabbily dressed individuals. In more than one community, the local homeless person would make a purchase in exchange for a few cigarettes out of the pack. It was not uncommon in affluent communities for strangers to buy youths cigarettes for free.

"I've had people like go into the store and I'll ask them before they go in. They'll say no. They'll come back out and throw me a pack of cigarettes, and not even ask me for the money."

Most of the 18 year old subjects in our study indicated that they would buy for younger kids. However, some indicated that they would not buy for kids who were under 14 .

\section{Commercial sources}

In some communities, high school aged youths relied upon parents and friends who were 18 years of age to buy them tobacco because it was just too difficult for them to buy themselves.

"Buying them yourself is kind of a last resort." 
In other communities, all of the high school aged subjects had friends who worked in stores or gas stations and had no difficulty buying tobacco. This appears to be the primary commercial source of tobacco in most of the communities studied. Knowing someone who worked in a store appeared to be the crucial factor distinguishing towns where youths could buy easily from those where they could not.

Moderator: "Do you all know somebody who works in a store in town?"

Subjects: "Yeah."

"If it's like kids who work there, they'll like give them to you."

"If you know someone who works at a gas station they'll usually sell to you if nobody's around."

Some youths who had worked as clerks indicated that they would sell to anyone, whether they knew them or not.

"I used to work there. People would just come in with IDs and they would be fake and they would use these IDs and I would just give it to them. You could tell they would be fake, though."

Subjects in many communities described a standard scam. If the boss is present, or if there is a surveillance camera, the clerk will ask for proof of age (ID). The underage buyer will then hand the clerk something that resembles an ID. The clerk will pretend to check the ID and return it to his friend. The sale will then be completed.

"A lot of times if I know someone, they'll be like, 'you're gonna have to bring an ID'. I'm like, 'yeah, all right, whatever', because, you know, they've got cameras there. So I just bring like, a library card and be, like, 'here you go'. 'All right, cool', you know."

Subject: "Yeah, but if you know the person there, they'll be just like, show me some kind of ID for the cameras."

Moderator: "And then what do you do?"

Subject: "Flash them a school ID. My license. A non-smoking card."

Moderator: "So, they ask but they don't really look at it?"

Subject: "Right... just for the cameras."

A non-smoking card entitles youths to discounts at participating businesses for pledging to remain non-smokers.

\section{Shoplifting}

Youths reported that shoplifting was much easier before local laws restricted self-service displays.

"There were these two stores near my house and I would ask for a Slushie. They would turn around to get it and I would snatch a pack of cigarettes. This was like around (age) 12 . Me and my brothers and sisters would do that all the time."

In the absence of self-service displays, the theft of tobacco by youths typically involves the clerk as the perpetrator or accomplice.

Store employee: "I took a carton once and sold them to people."

"People that like work at a big store, like Stop \& Shop, or something, they'll just run this scam. Someone like, I don't know, like J__ or someone will come up and say, give me like six cartons of cigarettes. They'll go over there and get six cartons and put them in a bag and say, ' 50 cents please,' and they'll just screw out of the store with six cartons, you know.”
"I used to know someone that used to work in a store and once in a while we'd all take a pack or something and she wouldn't care, like we'd leave her the money sometimes. Sometimes we'd just take them. She never really said anything. She didn't care."

Self-service displays contribute to access through an additional mechanism. Youths will serve themselves from the display and then throw some money on the counter and run out of the store before the clerk can challenge them.

\section{Locating a store that will sell to minors}

"If you go to the wrong store you're definitely going to get turned down, but most people who smoke know what stores to go to."

Youths learn from each other which stores will sell to minors. By hanging out with older smokers, novice smokers learn which stores will sell.

"That's because we've watched other people buy cigarettes that were underage for like years before we ever did it, so you kind of know what the ropes are."

Some used trial and error to find a store that will sell to them, but word of mouth was the most common method. It is clear that stores sell to youths who are known to them.

"It really doesn't matter which store, just as long as you know the person that works there."

"One gas station like, they knew like kids from this certain neighbourhood would always go in there and buy cigarettes. And they like basically knew all the kids, so you could always buy them there. You just got to get to know the people."

Many youths indicated that if a clerk sold to them once (often after presenting someone else's ID) they would continue to return to the same store when that particular clerk was on duty and would not be asked for ID again.

"My store, the guy didn't card me the first time. I just asked him and he gave them to me. They've been giving them to me ever since. The thing that sucks is, I can only go there on his shift."

Research has identified a variety of factors that predict a completed sale. ${ }^{19}{ }^{20}$ Our subjects identified the same factors through personal experience and put this knowledge to work when attempting to buy tobacco in unfamiliar territory. Subjects believed that it is easier to buy from gas stations and "mom and pop" convenience stores; it is easier to buy from young male clerks and at night. They believed that girls are more successful than boys; older youths are more successful than younger youths; employees are much more likely to sell than are managers. There was universal agreement that next to stores where their friends worked, stores owned by recent immigrants are the easiest places to buy tobacco.

\section{Purchasing strategies}

Some youths were convinced that practice had improved their rate of success. A common strategy is to walk in "like you do it all the time" and just expect that you will be able to buy.

"Look the clerk in the eyes."

Youths advised against asking for cigarettes but instead just said "A pack of Reds" (Marlboro's). Others were still unable to buy 
despite repeated attempts and felt that experience had not helped them. Youths lie about their age "all the time", and lie about having lost or forgotten their ID. They try to make themselves look older, and wearing a work uniform seems to help in this regard. When more than one youth is present, the one who looks the oldest is sent into the store. Dangling a set of car keys or showing a pack of cigarettes were common strategies. Some youths wait until a store is empty to try to buy, while others think success is more likely when the store is mobbed.

Youths commonly use their own ID or a borrowed one, having learned that clerks are careless.

“They don't even check. They don't even look at the pictures."

"They just look at the age. They don't look at your picture."

"I have my sister's ID (showing age 17) and I would use that since I was like 14, so I've been able to buy cigarettes and I've bought other people cigarettes, too."

"I just show my regular ID. It says I'm only 17, but they can't figure the years in their head."

Youths borrow an ID for one use, and if a sale is made, the youth can return to buy from the same clerk without showing the ID again. A very common and apparently successful ruse is to pretend to have an ID.

"I'd say that I'm 18, and I'd look in my pocketbook, and I'd be like, 'oh, I left it at home' and play along with it. I'd be like, 'I'll go and get it if you want' and I'd start to turn away and they'd be like, 'oh, it's all right, don't even waste your time'. I do that like, all the time."

\section{Black market}

In some communities, it was quite common for youths to buy and sell single cigarettes to each other. In other communities, this practice was considered distasteful as "smoker's hospitality" required you to share cigarettes when you had them. Several youths indicated that they or their friends would regularly steal cartons from the stores where they worked and sell the packs.

\section{Friends}

Friends were a source of tobacco for almost all subjects. When asked where their friends got their cigarettes, the two most common responses were that they bought them, or that the friend's parents provided them with cigarettes. This is consistent with a report by Wolfson and colleagues that having a mother who smokes or having recently attempted to purchase tobacco correlated with providing other children with tobacco. ${ }^{7}$ By the time youths are 16 or 17 , they all seem to have friends who have reached 18 and who will buy for them.

\section{Running out}

Because youths have a large social network of friends who will supply them with cigarettes, they rarely do without. Lack of transportation or money were the most common causes of running out. Some subjects hid cigarettes for a rainy day. The expense was perceived as a bigger obstacle than lack of access.

\section{Discussion}

Further efforts to reduce youth access to tobacco will require tighter controls on the sale of tobacco, as well as interventions to discourage parents from undermining the intent of youth access laws.

Among our subjects, parents and other older relatives were the primary source of tobacco during the initiation of smoking. This may help to explain why parental smoking is a strong risk factor for the uptake of smoking by adolescents. ${ }^{21}$ Youths who stole tobacco from a parent started smoking on average one year earlier than their peers. It is possible that the children of smokers then became the catalyst for smoking among their peers. It is especially disheartening to realise how many parents undermine the intention of youth access laws by buying tobacco for their teens or their friends. Parents must know that when they buy tobacco for their children's friends but not their children, the tobacco will be shared with their own child. This suggests that, for some, there are some feelings of guilt associated with more directly facilitating their child's addiction. The role of parents as suppliers of tobacco might best be addressed through mass media campaigns shaming this practice as bad parenting. More effective interventions are needed to convince smoking parents, and adults in general, that it is always inappropriate to provide tobacco to minors.

Asking strangers to buy tobacco appears almost universal at the junior high school level. Consistent with our data, a survey of California adults revealed that those who were most likely to be asked to purchase tobacco for a minor were those who were smokers, young (18-19 years), and with a low income. ${ }^{9}$ In a "shoulder tapping" experiment, $32 \%$ of 1285 adult strangers agreed to buy tobacco for underaged youths, and several provided youths with cigarettes at their own expense, as was reported by our subjects. ${ }^{12}$ The problem of adults buying tobacco for minors might be addressed through community education or through signs posted at the entrances of retail establishments stating the penalty for purchasing tobacco for a minor.

By the high school years, most underage smokers have friends who work in stores. High school age clerks represent the major factor contributing to illegal sales in most of the communities studied. A few clerks sell indiscriminately to minors, and facilitate or participate in theft. Our results are consistent with previous studies identifying shoplifting as a source of tobacco, but we are the first to report the complicity of underage clerks in this activity. $^{23411}$

When it comes to purchasing tobacco, many subjects thought experience is important and used a variety of tested tactics to improve their odds. These include lying about their age or their ID, using their own or a borrowed ID, dangling car keys, dressing to appear older, sending the oldest appearing youth in for a group, and acting confident. Youth's learn from one another where they can buy tobacco and they use the same store repeatedly. Some 
store clerks recognise neighbourhood youths and will sell to them if they think they will not be caught. Stores owned by recent immigrants are universally recognised as an easy place to buy. The ideal situation for an illegal sale is at a self-service gas station where there are no security cameras and a young male is working in the booth at night.

Standard compliance checks seriously underestimate the difficulty minors have in purchasing tobacco in their own communities. While youths employed by local health departments were turned down over $90 \%$ of the time during compliance checks, the youths living in these communities reported being turned down on average between "hardly ever" and "sometimes". In contrast to standard research methodology, youths do not make random attempts to purchase tobacco. They know which stores sell to minors. When in a strange town, they target their attempts based upon factors that increase the likelihood of a sale. Compliance surveys always use youths who are strangers to store personnel. By contrast, underage smokers indicate that knowing the clerk is the most important factor predicting success.

Protocols for compliance checks conducted for enforcement purposes should mimic the behaviour of underage smokers as closely as possible. ${ }^{22}$ A first step would be to use actual smokers for this purpose and to allow them to show an ID with an underage birth date..$^{22}$ Inspection protocols that exclude the use of IDs are too artificial; one quarter of our subjects had used an invalid ID to purchase tobacco. $^{22}$

Stores operated by recent immigrants should be targeted for more intensive education about the law and close monitoring of compliance.

The data from this study suggests that many current laws are too weak to reduce the availability of tobacco to minors effectively. Laws could be strengthened in the following ways.

(1) The minimum age for purchasing tobacco should be raised to 21 . In the communities where youths could not actually purchase tobacco for themselves, friends who had reached 18 years were the major social source of tobacco for high school students. In an unpublished survey of 539 high school students, Radecki found that $90 \%$ of the adults purchasing tobacco for minors were under 21 years of age ( $\mathrm{T}$ Radecki, personal communication, 12 January 1999). Raising the minimum age to 21 would address this problem directly and would make tobacco laws consistent with the national minimum drinking age.

(2) The minimum age for selling tobacco should also be set at 21. In communities where youths could purchase or steal tobacco from stores, the primary reason was that teenagers were working as store clerks. Entrusting the responsibility for tobacco sales to teenagers is like having the fox guard the hen house. In a recent study, illegal sales were 5.7 times more likely if the clerk appeared to be under 21 years of age than if the clerk appeared older. ${ }^{22}$

\section{What this paper adds}

While much is known about how youths obtain tobacco in the absence of strong enforcement programmes, this study is the first to examine sources of tobacco in communities with strong enforcement of youth access laws. In some such communities youths must rely completely on social sources of tobacco, with parents playing an important role. In other communities, illegal sales continue despite apparently high compliance rates as retail clerks continue to sell to youths who are known to them. Future efforts to reduce the availability of tobacco to youths should address the role of parents and whether teenagers should be trusted with the responsibility of conducting tobacco sales.

(3) Fines for illegal sales should be issued to the clerk in addition to the store owner. In many instances, illegal sales are made by store clerks who are intentionally violating their employer's policies and training instructions.

When making hiring decisions, store managers should be aware that teenagers and young men show the greatest predilection for making illegal sales, even with appropriate training. ${ }^{22}{ }^{24}$ Illegal sales are most likely to occur while the boss is away, but they also occur in their presence as teenage clerks pretend to check their friend's ID. Secret shopper programmes conducted while the manager is out of the store might help to identify problem employees. Employing older neighbourhood youths as secret shoppers might be most effective.

In interpreting this study, it is crucial to remember that the subjects in this study do not represent a random sample of youths from their communities. These are the youths who have been able to secure a source of tobacco despite strong enforcement by local officials. To the degree that strict enforcement of tobacco sales laws decreases tobacco use among youths, the subjects in this study would represent only those youths who proved immune to this intervention. Bias might have been introduced by the fact that our subjects were known by school personnel to be smokers. This suggests that they may have been less concerned about getting caught than other youths. Youths who are secretive about their tobacco use may have been excluded by the recruitment method used. Nevertheless, our data are very much consistent with previous studies. ${ }^{1-4}$ 6-8 11

This project was funded by the Substance Abuse Policy Research Program of The Robert Wood Johnson Foundation. The opinions stated here do not necessarily represent those of the sponsors.

1 Forster JL, Klepp KI, Jeffery RW. Sources of cigarettes for tenth graders in two Minnesota cities. Health Educ Res 1989;4:45-50.

2 Cismoski J, Sheridan M. Tobacco acquisition practices of adolescents in two Wisconsin communities. Wis Med $\mathcal{F}$ 1994:11:585-91.

3 DiFranza JR, Eddy JJ, Brown LF, et al. Tobacco acquisition and cigarette brand selection among youth. Tobacco Control 1994;4:334-8. 
4 Centers for Disease Control. Tobacco use and usual source of cigarettes among high school students-United States, 1995. MMWR Morb Mortal Whly Rep 1996;45:413-18.

5 Centers for Disease Control. Accessibility of tobacco products to youths aged 12-17 years- United States, 1989 and 1993. MMWR Morb Mortal Wkly Rep 1996;45:125-30.

6 Rigotti NA, DiFranza JR, Chang YC, et al. The effect of enforcing tobacco sales laws on youth's access to tobacco and smoking behavior: a controlled trial. $N$ Engl $\mathcal{F ~ M e d ~}$ 1997;337:1044-51

7 Wolfson M, Forster JL, Claxton AJ, et al. Adolescent smokers' provision of tobacco to other adolescents. Am f Public Health 1997;87:649-51.

8 Robinson LA, Klesges RC, Zbikowski SM. Gender and ethnic differences in young adolescents' sources of cigarettes. Tobacco Control 1998;7:353-9.

9 Ribisl KM, Norman GJ, Howard-Pitney B, et al. Which adults do underaged youth ask for cigarettes? Am F Public Health 1999;89:1561-4.

10 Emery S, Gilpin EA, White MM, et al. How adolescents get their cigarettes: implications for policies on access and their cigarettes: implications for policies
price. $\mathcal{F} \mathrm{Ntl}$ Cancer Inst 1999;91:184-5.

11 Harrison PA, Fulkerson JA, Park E. The relative importance of social versus commercial sources in youth access to tobacco, alcohol, and other drugs. Prev Med 2000;31:3948.

12 Klonoff EA, Landrine H, Lang D, et al. Adults buy cigarettes for underaged youths. Am F Public Health 2001 91:1138-9.

13 DiFranza JR, Carlson RR, Caisse RE. Reducing youth access to tobacco. Tobacco Control 1992;1:58.

14 Jason LA, Ji PY, Anes M, et al. Active enforcement of cigarette control laws in the prevention of cigarette sales to minors. $\mathcal{F} A M A$ 1991;266:3159-61.
15 Hinds MW. Impact of a local ordinance banning tobacco sales to minors. Public Health Reports 1992;107:355-8.

16 Forster JL, Murray DM, Wolfson M, et al. The effects of community policies to reduce youth access to tobacco. Am f Public Health 1998;88:1193-8.

17 Altman DG, Wheelis AY, McFarlane M, et al. The relationship between tobacco access and use among adolescents: a four community study. Soc Sci Med 1999;48:759-75.

18 DiFranza JR, Rigotti NA, McNeill AD, et al. Initial symptoms of nicotine dependence in adolescents. Tobacco Control 2000;9:313-19.

19 Clark PI, Natanblut SL, Schmitt CL, et al. Factors associated with tobacco sale to minors: lessons learned from the FDA compliance checks. $\mathcal{F A M A} 2000 ; 284 ; 729$ 34.

20 DiFranza JR, Savageau JA, Aisquith BF. Youth access to tobacco: the effects of age, gender, vending machine locks " 86:221-4.

21 Patten GC, Carlin JB, Coffey C, et al. The course of early smoking: a population-based cohort study over three years. Addiction 1998;93:1251-60.

22 DiFranza JR, Savageau JA, Bouchard J. Is the standard compliance check protocol a valid measure of the availability of tobacco to underage smokers? Am f Public Health (in press).

23 Landrine H, Klonoff EA, Alcaraz R. Asking age and identification may decrease minors' access to tobacco. Prev Med 1996;25:301-6.

24 DiFranza JR, Celebucki CC, Mowery PD. Measuring statewide compliance with tobacco sales laws: the Massachusetts experience. Am f Public Health 2001;91:1124-5.

\section{“Lateral Thinking” Pioneer Edward de Bono's gift to public health...}

"Cigarettes pin-pointed by UK scientist"

Household pins may be able to cut the damage done to people's lungs by cigarette smoking, says the Daily Mail. A Cambridge scientist has found that if pin holes are put into a cigarette about half an inch from the butt, the smoke becomes appreciably diluted with air. With three pin holes, harmful deposits of tar fall off by as much as 53 per cent. Forty habitual smokers experimented with the pin hole cigarettes to see whether they were smokeable. After three weeks 26 per cent of the smokers said cigarettes with three holes were not much different, 71 per cent said they were different but acceptable and 3 per cent said they were not worth smoking. Dr Edward de Bono, of the Dept of Investigated [sic] Medicine at Cambridge, thinks the test on the 40 smokers shows that cigarette smoking is very much a habit and not a matter of taste, the newspaper said. "The pin hole may be a good way of getting people to accept weaker cigarettes or really effective filters", he said. Smokers seem to be able to accept the air-diluted cigarettes because you can get used to them graduallyone hole one week, two the next, and so on. "The people in my experiment found it very difficult and unpleasant to return to an ordinary cigarette after smoking a four-pin-prick model."

The Retail Tobacconist (Australia) May 1965:10. 